\title{
Pascal couRTADE et Isabelle SAINT-MARTIN (dir.), L'expression du religieux dans la sphère publique: comparaisons internationales
}

Paris, La Documentation française, 2016

\section{Olivier Saly-Rousset}

\section{OpenEdition}

\section{Journals}

Édition électronique

URL : https://journals.openedition.org/rdr/531

DOI : $10.4000 /$ rdr.531

ISSN : 2534-7462

\section{Éditeur}

Presses universitaires de Strasbourg

\section{Édition imprimée}

Date de publication : 31 octobre 2017

Pagination : 200-202

ISBN : 978-2-86820-974-0

ISSN : 2493-8637

\section{Référence électronique}

Olivier Saly-Rousset, «Pascal courtade et Isabelle saint-MARTIn (dir.), L'expression du religieux dans la sphère publique : comparaisons internationales », Revue du droit des religions [En ligne], 4 | 2017, mis en ligne le 15 janvier 2020, consulté le 23 mai 2022. URL : http://journals.openedition.org/rdr/531 ; DOI : https://doi.org/10.4000/rdr.531

Ce document a été généré automatiquement le 23 mai 2022

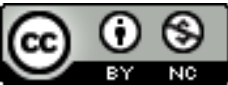

La revue du droit des religions est mise à disposition selon les termes de la Creative Commons Attribution - Pas d'Utilisation Commerciale 4.0 International - CC BY-NC 4.0. 


\title{
Pascal COURTADE et Isabelle SAINT-
} MARTIN (dir.), L'expression du religieux dans la sphère publique : comparaisons internationales

Paris, La Documentation française, 2016

\author{
Olivier Saly-Rousset
}

\section{RÉFÉRENCE}

Pascal COURTADE et Isabelle SAINT-MARTIN (dir.), L'expression du religieux dans la sphère publique : comparaisons internationales, Paris, La Documentation française, 2016, 222 p.

1 Cet ouvrage collectif nous invite à nous pencher sur un débat qui prend de plus en plus de place dans l'actualité. Ces dernières années, de nombreuses affaires juridiques ont suscité de nouvelles interrogations concernant le droit à exprimer publiquement son appartenance religieuse. Pour cerner au mieux l'étendue du problème, les auteurs tentent, non sans succès, de déterminer précisément le cadre dans lequel le principe de laïcité est en mesure de s'appliquer. Ainsi, les différentes contributions abordent cette question de la capacité propre à chacun d'exprimer ses croyances religieuses dans la sphère publique. Différents angles sont abordés, au travers de quatre grandes parties qui prennent en considération les différentes problématiques. La première se charge ainsi d'analyser la neutralité de l'État français tout en comparant ses stratégies avec celles de l'État allemand (Alfred Grosser), ainsi que la notion de laïcité à l'échelle européenne (Philippe Portier). La seconde partie se penche sur les manifestations religieuses dans l'espace public et sur la question de la foi dans la vie de tous les jours. L'entreprise et le lieu de travail sont des lieux clés pour comprendre la question de la neutralité religieuse. De la même manière, la question de la laïcité à l'école est abordée dans la troisième partie par le biais des politiques française, belge (Xavier Delgrange) et 
anglaise (Julia Ipgrave). La fin de l'ouvrage s'interroge sur la place que les croyants peuvent occuper au sein de la société européenne. Ces diverses recherches tentent de prendre la pleine mesure du problème de la laïcité par le biais d'appréciations philosophiques, sociologiques et bien entendu juridiques. Le choix de comparer la politique de différents pays est également une idée judicieuse opérée par les auteurs, afin de donner à la question un éclairage international.

2 Contrairement aux idées reçues, la laïcité n'est pas seulement une contrainte de neutralité imposée à l'État à l'égard des religions. L'année 2014 s'est révélée propice à l'analyse des nouveaux enjeux et problématiques liées à la laïcité. L'affaire Baby Loup, l'arrêt de la CEDH concernant la loi française relative à l'interdiction de dissimuler son visage dans l'espace public et les problèmes liés aux crèches de Noël en sont de parfaits exemples (Thomas Andrieu). L'important est de savoir définir ce qui est religieux ou non. De la même manière, la notion de sphère alimente un débat sur sa portée, de par son caractère multidimensionnel. À titre d'exemple, l'entreprise et le lieu de travail peuvent être assimilés dans une certaine mesure à la sphère publique. JeanLouis Bianco explique qu'il est nécessaire de distinguer quatre types d'espaces (p. 31). L'espace privé permet une liberté cantonnée au respect de la loi. L'espace administratif correspond à la zone de l'État, ses sous-groupements et les lieux où il exerce ses activités administratives. L'espace partagé renvoie à une forme d'espace commun, mais cette fois-ci public, à l'image de la rue. Enfin l'espace social représente les lieux de travail communs comme l'entreprise. Cette dernière a suscité de nombreuses interrogations, car bien qu'étant un espace privé, elle doit aussi se plier dans une certaine mesure aux exigences de la laïcité. D'après Hubert des Longchamps, le phénomène religieux a un impact sur la société civile dans laquelle nous travaillons (p. 118). La question relèverait donc de la responsabilité de chacun.

3 La laïcité s'applique donc différemment selon la catégorie d'espace visée. Elle ne sousentend pas un contrôle des religions par l'État, mais plus simplement une liberté de culte applicable à tous de façon identique tout en respectant l'ordre public établi. À ce titre, l'interdiction du port de signes religieux ostensibles dans les écoles est destinée à permettre d'éviter chez les enfants des pressions, «afin qu'ils puissent ensuite faire librement leurs choix» (Jean-Louis Bianco, p. 33). Dans le but de réduire d'éventuels risques de désunions liées aux croyances et aux convictions, les États européens ont mis au point ce que Philippe Portier nomme la « solution laïque » (p. 78). Le but est d'éviter toute forme de discrimination du fait d'être croyant ou non. Les États européens agissent différemment au sein de leurs territoires en fonction des problèmes spécifiques liés à leurs situations respectives. Depuis la seconde guerre mondiale, l'Occident a selon Gérard Bouchard, tenté « un important consensus [...] en faveur du respect de la diversité » (p. 93). Le pluralisme s'en est retrouvé renforcé.

4 Cette stratégie se traduit par de nombreuses négociations conclues généralement entre les citoyens, mais également par des accommodements issus du pouvoir légal comme cela peut être le cas au Québec (Gérard Bouchard). De même, la France semble avoir abordé la question avec une certaine rigueur par le biais de textes comme la loi de 1905, ou par une jurisprudence stable à propos de la manifestation d'une appartenance religieuse. La neutralité du domaine public doit, selon Patrice Rolland, s'imposer en ce qui concerne les signes et emblèmes que l'on voudrait y implanter. Ces pratiques touchent principalement les personnes publiques. Pour leur part, les personnes privées ont « un véritable droit à la visibilité et à l'extériorisation dans le respect de l'ordre 
public et des droits égaux d'autrui»(p.121). De nouvelles interrogations sont cependant nées en raison du développement d'une pratique individualisée du culte loin des institutions officielles de la religion. De même, la qualification exacte de l'espace public semble continuer à susciter des interrogations. Soit il s'agit d'un espace commun à tous où chacun est libre d'exprimer ses convictions, soit il s'agit d'un lieu de visibilité. Dans ce cas, il y a à craindre d'éventuelles pressions morales notamment par le biais d'une expression exacerbée de la foi. De nouveaux compromis semblent donc nécessaires afin de concilier les exigences de chacun. L'exemple d'autres pays comme le Québec semble plus que jamais nécessaire à observer afin de trouver des idées nouvelles.

\section{AUTEURS}

\section{OLIVIER SALY-ROUSSET}

Vacataire en droit public, Université de Perpignan Via Domitia, Centre du droit économique et du développement (CDED) 